\title{
A AVALIAÇÃO ESCOLAR AINDA É UM PROBLEMA SOCIOCULTURAL
}

\author{
English Title: The problems ethics of evaluation of studens in post-modern society
}

doj> 10.33726/akdpapers2447-7656v10a62020p115-138

PESSOA, Marcelo² - iD https://orcid.org/0000-0002-9193-4604

RESUMO: Nesse artigo trazemos à tona uma discussão que trata de um dos maiores problemas do ensino em todos os níveis: a avaliação do rendimento da aprendizagem. Justifica a realização de um estudo como esse, o fato de que, tendo, como pedra de toque, considerações pessoais do próprio autor sobre a ética e a sociedade contemporânea, se fez necessária a propositura de uma alternativa para o problema do "como", do "quando" e do "que" se avaliar no processo de ensino, principalmente na esfera das Ciências Humanas e Ciências Sociais. Como resultados deste estudo, escrevemos um paper, o qual foi vencedor de um concurso de Artigos Científicos, em nível nacional, promovido pelo Rotary Internacional, no ano de 2008. Naquele ano, a temática central do texto apresentou o objetivo de realinhar as práticas de avaliação no Brasil, por meio de uma revisão sistemática de postulados e, no final do processo, culminou por se encontrar com um novo modelo de compreensão sobre o que pudesse ser a avaliação escolar. No presente reprint, após intervalo maior que uma década, uma leve complementação foi inserida, combinando o que já estava escrito à sutileza dos argumentos de Barros Filho (2015), na obra: Somos Todos Canalhas.

\section{PALAVRAS-CHAVE: Avaliação, Ética, Educação}

ABSTRACT: In this article, we bring up a discussion that addresses one of the biggest teaching problems at all levels: the assessment of learning performance. It justifies the realization of a study like this, the fact that, having as touchstone, the author's personal considerations about ethics and contemporary society, it was necessary to propose an alternative to the "how" problem, the "when" and "what" to evaluate in the teaching process, mainly in the sphere of Human Sciences and Social Sciences. As a result of this study, we wrote a paper, which won a national scientific paper contest, promoted by Rotary International, in 2008. That year, the central theme of the text presented the objective of realigning the practices of evaluation in Brazil, through a systematic review of postulates and, at the end of the process, culminated in finding a new model of understanding about what could be school evaluation. In the present reprint, after an interval of more than a decade, a slight complementation was inserted, combining what was already written with the subtlety of the arguments of Barros Filho (2015), in the work: "Somos Todos Canalhas".

\section{KEYWORDS: Evaluation, Ethics, Education}

${ }^{1} \mathrm{O}$ título original do paper era: "Os problemas éticos da avaliação escolar na sociedade pós-moderna", e foi publicado na Revista Ideal de Servir (ISSN 1983-554X, v.1, versão print, 2008, p. 09-28). Tratou-se de tiragem única, criada como resultante de um Concurso Nacional de Artigos Científicos, patrocinado pelo Rotary Internacional (2007), Distrito 4770, sobre o tema da "Ética nas Instituições". Integraria o volume, os dez melhores colocados, e este trabalho foi o vencedor (http://www.cassilandianoticias.com.br/ultimas-noticias/e-de-sao-jose-do-rio-preto-o-ganhador-do-

concurso-do-ri). Como o periódico supra foi uma publicação restrita, sob o ponto de vista de seu públicoalvo - sem acesso ao meio acadêmico, e existente somente no modo impresso, e ainda, mesmo nos dias atuais, as referências na internet estejam desaparecendo, julgamos pertinente revisitar a publicação, em função da relevância temática sobre a qual a escrita original se debruçou, revisando conceitos e linguagem (adequando itens à Reforma Ortográfica de 2009) e republicando o seu conteúdo em repositório digital, dando-lhe novas citações, novo título e uma URL com maior persistência.

${ }^{2}$ Doutor em Letras pela Universidade Estadual de Londrina. Orientador e Docente na UEMG - Unidade Frutal. Departamento de Linguística, Letras, Comunicação e Artes - DLLCA. 


\section{INTRODUÇÃO}

Os domínios do emocional vão dilatando-se à medida que débeis se tornam as bases educacionais (SÁ, 2007, p. 119).

Nosso texto se enquadra no âmbito das discussões sobre a ética e a dinâmica sociocultural do ensino e da aprendizagem, em qualquer nível da produção e difusão do conhecimento, na esfera pública ou particular da educação. Dessa abordagem genérica deriva nossa preocupação específica quanto à natureza contemporânea do instrumento avaliação ${ }^{3}$, nos termos de que a partir desse instrumento esperamos obter parâmetros confiáveis qualitativos e/ou quantitativos sobre a evolução da aquisição de conteúdos por parte do público discente, sujeitos integrantes da estrutura de ensino organizada pelos gestores do sistema educacional. No fragmento a seguir, estão sintetizadas as principais indagações às quais este paper pretende elucidar:

Sempre me intrigou que um aluno qualquer que compareceu durante todo o semestre, participou das aulas, manifestou-se, ganhou repertório e conservou lacunas possa ter uma avaliação traduzida em um único número entre zero e dez. Sete, por exemplo. Ora, o que efetivamente aconteceu? Bem, foi aplicada uma prova. Fica estabelecido por um acordo tácito que as questões que compõem essa prova e suas respostas são representativas de todo o desempenho do aluno. Realizada a prova, o professor faz a correção. Em que consiste esse procedimento? Em verificar - de forma mais ou menos rigorosa - a equivalência entre as respostas dadas pelo aluno e aquelas consideradas corretas pelo docente. No caso de uma prova de múltipla escolha, essa verificação é imediata e mecânica. No caso de uma prova dissertativa, a comparação é mais trabalhosa e sutil. Mas em qualquer tipo de prova a nota do aluno resulta de uma comparação com uma prova de referência: o gabarito da prova. Este exemplo nos permite propor algumas questões. Será que para atribuir valor a outras coisas diferentes de uma prova - realizamos procedimento semelhante? Será que todo valor pressupõe uma comparação com alguma referência considerada nota dez? (BARROS FILHO, 2015, p. 09).

Convive numa espécie de universo paralelo a tais questões e subjacente à totalidade abrangente do processo de convivência social na sociedade pósmoderna, as premissas da disciplina e a da manutenção do status quo

\footnotetext{
Note-se que a avaliação, nos moldes tradicionais, é subjetivamente empregada como estatuto disciplinador de condutas, embora objetivamente esse instrumento tenha a feição de mecanismo aferidor de compreensão e assimilação de conteúdos escolares.
} 
apresentadas a seguir, nos termos de DREYFUS e RABINOW (1982), instituem um lócus argumentativo, donde temos que as controvérsias suscitadas sobre a contingência do "como", do "quando", e do "que" avaliar durante o processo de interação social, ficam ideologicamente mais aquecidas, como é exato caso de se avaliar ou parametrizar processo de ensino:

O objetivo do "poder disciplinar" consiste em manter "as vidas, atividades, o trabalho, as infelicidades e os prazeres do indivíduo", assim como sua saúde física e moral, suas práticas sexuais e sua vida familiar, sob estrito controle e disciplina, com base no poder dos regimes administrativos, do conhecimento especializado dos profissionais e no conhecimento fornecido pelas "disciplinas" das Ciências Sociais. Seu objetivo básico consiste em produzir "um ser humano que possa ser tratado como um corpo dócil" (DREYFUS e RABINOW, 1982, p. 135, apud HALL, 2006, p. 42).

Dreyfus e Rabinow (1982), acima, fala-nos de uma "ética do poder" orientada pela manutenção da disciplina, a qual é tutelada pelas técnicas de avaliação, a partir do que o pensamento hegemônico acredita poder ter uma medida do que se aprendeu sobre os conteúdos escolares, mas, o que se verifica, é que a avaliação, assim compreendida, isto é, sob um viés de falsa objetividade, atua mais a serviço de informar o quanto o indivíduo está ou não adaptado a um modelo social e educacional precário ao qual está inserido do que na direção de dar contribuições honestas no sentido de instruir:

Sobrecarregada com o saber histórico, a consciência moderna perdeu a "força plástica da vida", que permite ao homem "interpretar o passado a partir da força suprema do presente", com os olhos no futuro. Visto que as ciências do espírito que percorrem um caminho metodologicamente equivocado prendem-se a um ideal de objetividade falso, isto é, inatingível, neutralizam os critérios necessários à vida e difundem um relativismo paralisante [...] (HABERMAS, 2002, p. 124).

Essa disciplina (ou conduta de anuência) pode ser garantida de vários modos. Contudo, na instituição escola, dentro da sala de aula, as técnicas de avaliação são contrárias à ética, pois são comumente empregadas como instrumentos de coerção que conduzem os "não aptos" para a exclusão. 
A coerção está oculta no sistema como um todo e, vez ou outra, "escapam" nas falas docentes do tipo "olha, se não fizerem silêncio, aplico prova surpresa, hein!".

E nisso, tem-se, portanto, um horizonte conturbado de "porquês" em que as tensões socioculturais tramitam no percurso do desejo contemporâneo de se verificar a lógica das próprias matrizes diretivas de ambientes controlados, como os da escola, sua estrutura social e os sustentáculos ideológicos destas mesmas instituições:

Chamamos "estruturado" um espaço dentro do qual alguns eventos são mais prováveis acontecer que outros. É nesse sentido que a "sociedade" é "estruturada" - uma ilha de regularidade no mar da casualidade. Essa regularidade precária só pode existir como produto contínuo e perpétuo da pressão "socializante" [...]. Toda organização social, grande ou pequena, societário-global ou local e funcionalmente específica, consiste em sujeitar a conduta de suas unidades a critérios, instrumentais ou processuais, de avaliação (BAUMAN, 1997, p. 143).

Dentre essas matrizes, é pertinente questionar-se, portanto, no âmbito da instituição escola (recuperando uma das questões de Barros Filho - 2015), sobre a real eficácia da avaliação como instrumento de aferição do conhecimento, o que, por si só, já se mostra como dificuldade, uma vez que essa pretensa objetividade da avaliação, notadamente nas ciências do espírito, como vimos acima com Habermas, figura-se como algo "inatingível".

Isto ocorre porque nem sempre é possível se transpor e quantificar em números absolutos e objetivos a extensão do aprendizado do ser humano, que é o sujeito ativo do conhecimento:

Podemos ainda pensar de outra forma. O caso mais óbvio de julgamento [tal qual o que se faz numa "prova" escolar - adendo meu] talvez seja o do juiz, que diante de um caso concreto não sabe muito bem o que fazer. Por dois motivos: ou ele não entendeu bem o caso e, por isso, não se sente seguro para julgar porque não sabe ao certo o que está em julgamento - e nesse caso trata-se de um problema de interpretação dos fatos a serem valorados - ou então ele tem dúvida quanto à lei, quanto ao critério que deveria balizar seu julgamento. $\mathrm{O}$ fato é que, seja pela incompreensão do objeto à sua frente ou pela inexistência de um critério adequado de julgamento, um gabarito, o ato de se atribuir valor a alguma coisa torna-se impossível (BARROS FILHO, 2015, p. 11). 
O que se vê, ao contrário do que se espera e avalia, é que o homem aprende por meio de uma grandeza essencialmente abstrata e subjetiva, o que por si só já torna a avaliação objetiva instrumento de aferição ineficaz ou no mínimo inadequado para o fim a que se propõe.

Dependendo ainda da maneira que as técnicas de avaliação são empregadas como métodos de imposição disciplinar, os efeitos podem ser especialmente nocivos, uma vez que podem contribuir decisivamente para a ratificação de outro fenômeno educacional: a exclusão social via escola. Por meio de uma "avaliação", não se exclui para "fora" da escola, mas pratica-se uma exclusão "para dentro", em que o sujeito ativo do conhecimento se torna paciente, alijado do sistema por uma natural inépcia que é do aparato avaliativo proposto ao qual foi submetido, e não dele, sujeito avaliado ( $v$. g.: BARROS FILHO, 2015, p. 11):

Os pobres querem ascender para ficarem ricos, trabalham e estudam simultaneamente, consagrando noites e fins de semana ao estudo. Mas são esses pobres que justamente pagarão seus cursos (pois, muitos dos cursos noturnos e particulares cobram altas taxas de seus alunos) [e ele foi, assim, "excluído para dentro" do sistema de ensino] ao contrário dos ricos que, para permanecerem ricos, procuram ocupar as vagas dos poucos colégios estaduais gratuitos que na maior parte das vezes funcionam de dia (FREITAG, 1980, p. 67).

Lançando nosso olhar para essa provável "ética da exclusão" via instituição escola, não estamos aqui dizendo que a avaliação seja a única responsável pelas exclusões (para dentro ou fora do sistema), tampouco que o capitalismo ou que os professores são os vilões desse sistema, mas sim que todos também fazem parte do delineamento do histórico desse problema:

Esta reflexão não serve para caracterizar o magistério e outras carreiras e a sofrida classe do magistério do ensino básico e fundamental. Conseguiu-se, em algumas décadas, proletarizar o professor, hoje mal remunerado, sem perspectivas de carreira, sem possibilidade de continuar seus estudos e às voltas com um alunado a cada dia mais rebelde, indisciplinado e sem limites (NALINI, 2001, p. 225).

Em suma, as duas citações anteriores aparecem aqui a título ilustrativo desse estado da arte da exclusão de discentes e de docentes via práticas de 
salas de aula, mas é conveniente lembrarmo-nos ainda de um trecho da história vivida por Helen Keller (autora abaixo citada) e sua professora, nos idos de 1880, situação que complementa nosso raciocínio e que não dista muito do que Nalini (2001) asseverou anteriormente:

Lamento profundamente que A História de Minha Vida tenha sido descuidada no que escrevi acerca dos meus progressos em adquirir vocabulário e em aprender a falar. [...] Com surpreendente rapidez, a criança passou da luz à escuridão e se transformou num fantasma. $O$ vento deixou de ter voz para ela, o silêncio apoderou-se do seu espírito, pairando sobre o espaço em que ela se movimentava. A aridez mental se apossou do seu ser. As suas palavras feneceram. [...] A família permanecia impotente diante daquela inteligência frustrada, quando as mãos do fantasma se estendiam para tocar as formas que podia alcançar, mas que nada significavam (KELLER, 1957, p. 43).

Vemos que as nuances comportamentais e disciplinares são embaladas, também, pelas considerações que podem ser feitas em torno estado da arte da avaliação ${ }^{4}$ silenciosamente repetido pelo sistema no dia-a-dia.

A inexatidão decorrente da praxis avaliativa emerge conflitante, justamente porque os pontos de vista com relação a ela divergem em muitos pontos na lide diária da educação. Por isso, propomos aqui falar-se numa "ética da avaliação", em que possamos concentrar os esforços de solução do problema, por exemplo, na seleção de quais seriam os melhores temas transversais, ou sobre o "como" ensinar o melhor e o mais adequado conteúdo em dado curso ou disciplina, qual seria o melhor livro didático, a abordagem didática ideal, a estrutura física perfeita, qual a melhor estratégia de convivência e interação do discente com a instituição escola:

A nova escola de ensino médio não há de ser mais um prédio, mas um projeto de realização humana, recíproca e dinâmica, de alunos e professores ativos e comprometidos, em que o aprendizado esteja próximo das questões reais, apresentadas pela vida comunitária ou

\footnotetext{
${ }^{4}$ Quanto às considerações sobre o estado da arte da avaliação, salientamos que optamos nesse texto por um alinhavo mais afeito à interdisciplinaridade. Isto é, para que mantivéssemos o foco sobre a discussão em torno do paradigma interdisciplinar da pós-modernidade, deixamos de lado os comentários objetivos sobre o repertório acumulado quanto à avaliação, abrindo caminho, assim para o escopo ético do emprego do modelo avaliativo vigente em suas implicações socioculturais. Privilegiamos, assim, de forma mais abrangente, as personagens envolvidas no processo sociocultural de convivência, dando menor destaque aos argumentos do sistema de avaliação vigente, o qual rotularíamos de antiético, uma vez que nivela objetivamente sujeitos que são de índole subjetiva.
} 
pelas circunstâncias econômicas, sociais e ambientais. Mais do que tudo, quando fundada numa prática mais solidária, esta nova escola estará atenta às perspectivas de vida de seus partícipes, ao desenvolvimento de suas competências gerais, de suas habilidades pessoais, de suas preferências culturais ( $P C N+$, Ensino Médio, p. 11).

Dentro desse horizonte de perguntas, que envolve uma gama de atores que tem origem na família, passando pela sociedade, desembocando na Escola, fazemos um recorte sobre o tópico "Escola", e dele retiramos o tema avaliação. É nele que centramos os argumentos de nossa sucinta exposição, por acreditarmos que essa instituição pertence a um rol amplo de dissensões abarcadas no universo da convivência social que aflora na esfera do ensino.

\section{O PROBLEMA ÉTICO E SOCIOCULTURAL DA AVALIAÇÃO}

O tema da "ética na avaliação escolar" sugere, como vimos, que se aí há um problema, ela certamente estará socioculturalmente enraizado no modelo de se tentar medir o que é por natureza imensurável. Isto é, mensurar o volume do conhecimento adquirido por um aprendiz, por si só, suscita polêmica nas esferas psíquica e cultural. Para encetar nossas reflexões, cremos que seja válido salientar outros posicionamentos para alimentar esta discussão.

Assim, já partiremos da intrigante premissa, de que todo estudante é um devedor, inicialmente insolvente, da comunidade por ele integrada, uma vez que, para assegurar-Ihe vaga no sistema reconhecido de educação regular, o país investiu consideravelmente (NALINI, 2001, p. 223).

O corpo discente normalmente não tem consciência dessa "ética social da retribuição", da qual nos fala acima Nalini (2001). Os alunos frequentam a Escola por toda uma vida sem ter a mínima noção de que seu papel social nela é muito mais abrangente do que simplesmente o de decorar fórmulas, ler livros, fazer provas, passar no vestibular e pendurar um diploma na parede de casa.

Os estudantes pensam que devem "retribuir" ao Estado e à sociedade o investimento até então feito, porém, não têm consciência de que sua retribuição não deveria se prender ao fato de ter que devolver algo para serem politicamente corretos. $O$ que eles talvez pudessem pensar, é se não haveria um modo de tornar o aprendizado mais atraente para si próprios e, assim, ao 
invés de construírem uma "ética da retribuição", quem sabe, conseguissem formular um melhor hábito de aprendizagem.

Isto se assemelha ao fato narrado por Barros Filho em sua obra (2015). Diz ele que, certa vez, indo a um programa de televisão, em que se difundia a história de um sujeito que ao encontrar dinheiro na rua, prontamente se prontificou a devolver o achado ao verdadeiro dono. Nisso, Barros Filho fora convidado a emitir um "parecer" sobre o fato. O que se esperava dele, se não uma óbvia retribuição?

A apresentadora, gentilíssima comigo, com a pauta na mão, aguardava ansiosa meu óbvio veredito. Paciência. Fui obrigado a dizer que não só não havia nenhuma relação de causalidade entre agir bem e ser feliz depois, como também não deveria haver na boa ação nenhuma expectativa de felicidade posterior. Porque a boa conduta dependia simplesmente de uma verdade embutida nela mesma. Tipo devolver o dinheiro por devolver o dinheiro. Porque é isso que deve ser feito, o que nada tem a ver com os encontros alegres e tristes do dia seguinte (BARROS FILHO, 2015, p. 109).

Logo, o que se esperar de um estudante, então, diante de uma avaliação, se não uma óbvia retribuição por parte dele em relação à sociedade que nele investiu tantos recursos? Do mesmo modo que não poderia haver expectativa de felicidade futura numa devolução de dinheiro, não se pode instituir indicativo de evolução mental ou intelectual após a realização de provas escolares, por que a boa aprendizagem deve depende simplesmente de uma verdade embutida nela mesma, ou seja, a verdade da aprendizagem reside no próprio ato de aprender.

Portanto, é mais que esperado que, dessa falta de sintonia entre sujeito histórico e sociedade, se possa dizer que se origina um problema que engloba tanto a "ética da avaliação" quanto a "ética da retribuição social".

\section{NA PRÁTICA, COMO SE DARIA ISSO?}

A situação, então, seria a seguinte. Se, eventualmente, uma avaliação, num determinado período didático - o bimestre, por exemplo -, de uma disciplina, de um determinado curso, apresentar "números" (tais como notas bimestrais, gráficos, estatísticas) homogêneos (zero, oito ou dez, de fora a fora 
da lista de nomes dos alunos matriculados na disciplina), isso pode não querer dizer, necessariamente, que o avaliador tenha considerado todos os alunos como entidades iguais, mesmo que sob a ótica da "ética da retribuição social" devessem sê-lo. Do mesmo modo, as notas iguais não significaria que todos atingiram (no caso de todos eles perceberem notas elevadas, acima da média exigida pela burocracia para a aprovação) ou não atingiram (no caso de todos eles perceberem notas ruins, ou abaixo da média estipulada) uniformemente os índices propostos.

Isso talvez pudesse apenas afirmar, que os números podem exprimir 0 fato de que podem ou não ter atingido os objetivos, tentando alcançá-lo de maneiras distintas uns dos outros. Os números apontados nas planilhas de notas não diriam respeito aos estudantes, mas, sim, ao estágio em que eles se encontram na caminhada em direção a um dado objetivo. Digamos que um grupo tivesse a missão de sair de São José do Rio Preto - SP, indo para a capital, São Paulo. Sabe-se que entre estas duas cidades há uma distância de $454 \mathrm{Km}$. Logo, quando o viajante ou o grupo de viajantes tiver percorrido 257 $\mathrm{Km}$, terão cumprido $50 \%$ da meta traçada. Para isso, poderíamos aferir um número correlato, tal como "nota 5". E, assim que a distância fosse sendo cumprido, o valor atribuído em relação ao avanço na direção do objetivo não às pessoas iria sofrendo alterações, independentemente do modo como elas estivessem viajando (a pé, de carro, de ônibus, de avião, de trem, de patinete, de skate etc.), pois, cada um teria um modo particular de cumprir sua meta, segundo as habilidades e competências de cada um:

Isso igualmente implica que o professor deva aceitar o aluno tal como é e compreender os sentimentos que ele possui. Aceitando o aluno e compreendendo-o empaticamente, o professor fará, de sua parte, tudo para a criação de um clima favorável de aprendizagem. Dessas condições, a autenticidade e congruência são pessoais do professor. As demais - aceitação e compreensão - são emergentes do relacionamento professor-aluno. Todas essas condições, no entanto, implicam habilidades e um saber ser e ajudar. São passíveis de treinamento. As atitudes podem ser implementadas na prática. $\mathrm{O}$ aluno deve responsabilizar-se pelos objetivos referentes à aprendizagem, que têm significado para ele, e que, portanto, são os mais importantes. A autoconstrução do indivíduo se fundamenta na tendência atualizante do organismo (procura de autorrealização) e na capacidade de regulação do indivíduo (MIZUKAMI, 1986, p. 52). 
Noutros termos, vemos, já há muito tempo, que as notas iguais dadas aos discentes não refletem a índole objetiva de resultados objetivamente iguais ou diferentes que por eles poderia ser obtida, mas uma subjetividade da "ética da premiação" atribuída coletivamente por metas desejadas e pactuadas globalmente, as quais foram atingidas segundo os critérios do professor, dos responsáveis, do Estado, da instituição de ensino, do gabarito de um material didático, itens estes que funcional de forma isolada ou cumulativa:

\begin{abstract}
Antes de iniciar seus esforços para atingir uma nova meta, escolha uma recompensa para se oferecer quando realizar seu objetivo. Isso fará você desejar ainda mais ser bem-sucedido, fazendo com que o novo comportamento seja reforçado, mesmo que, a princípio, os outros não percebam ou não apreciem. A recompensa deve ser algo que você realmente esteja desejando: uma roupa nova, um disco, um livro, um jantar num determinado restaurante, uma caminhada nas montanhas, um mergulho no mar, um fim de semana num lugar agradável, uma hora para cuidar das plantas [boas notas] (MALDONADO \& GARNER, 2000, p. 147).
\end{abstract}

Desse modo, dois alunos, apesar de perceberem notas iguais, podem perfeitamente estar em momentos distintos da assimilação dos conteúdos (ou dos objetivos) sugeridos e, contudo, podem, do mesmo modo, estarem contribuindo para o sucesso de uma empreitada acadêmica, cultural ou social. Suas notas, nesse caso, representam prêmios justos por objetivos pessoais atingidos. Isto é, neste caso, as notas ou a premiação refletem menos uma satisfação a ser dada à burocracia escolar, e mais uma necessidade íntima de autorrealização da pessoa.

No escopo dessa proposta, portanto, vê-se a propositura de uma "ética para a avaliação", em que o ser humano é posto em apartado ao critério meramente burocrático e numérico da nota: o suor, a boa forma física e o reconhecimento por seus pares premiam o esforço e a autodeterminação do atleta, a medalha, o reconhecimento público e a relevância histórica do ato atestam $o$ atingimento total das metas.

O que aparentemente pode assustar nessa "ética para a avaliação" ora proposta em nosso paper pode ser o fato de que, assim considerando, abrir-seia mão do critério numérico absoluto e objetivo do atual formato de avaliação, e 
adotar-se-ia um critério relativo e subjetivo, por meio do qual seriam avaliados não os alunos, mas o ritmo e estágio de consecução dos objetivos poderia desestabilizar o sistema educacional.

Teríamos, assim, não alunos nota 02, 07 ou 10, mas objetivos alcançados em 20\%, 60\%, 75\% ou 100\%, dependendo da situação, do contexto sociocultural, da etapa do cronograma de execução do projeto, e assim por diante. Embora inicialmente apavorante (visto que tudo que é novo espanta), essa nova ética avaliativa privilegia a inclusão social do sujeito ativo do "aprender", tanto para dentro quanto para fora da escola, pela diferenciação dos alunos a partir de objetivos e não pelas notas obtidas. O que talvez esteja faltando, neste sentido, é uma proposta metodológica de avaliação de conteúdos apreendidos que contemple as sabidas diferenças entre discentes:

As escolas que, em diferentes ambientes e condições, estão construindo novos e bem-sucedidos paradigmas educacionais não são necessariamente as mais ricas, nem as mais bem-equipadas. $O$ que as distingue é a sintonia entre professores, alunos e comunidade, a atenção solidária dada às metas de diferentes conjuntos de alunos (como a orientação profissional para alguns, o preparo pré-universitário para outros) e a realização cultural e social, construída no próprio convívio escolar, e não adiada para um futuro distante $(P C N+$, Ensino Médio, p. 11).

A esse respeito, é interessante notar que a prática docente é correlata no nível superior do ensino, dentre as diversas gradações possíveis nos vários níveis do ensino, poder-se-ia, por exemplo, no início de cada ano letivo, propor aos alunos metas bimestrais, semestrais e anuais a serem alcançadas por todos que nela se engajassem. A reforma Fernando de Azevedo, entre 1927 e 1930, já previa esse sistema de interação com os saberes:

Funcionando como uma sociedade em miniatura, a escola ensinaria os alunos a "viver em sociedade e a trabalharem em cooperação. $\mathrm{O}$ aluno não deve exercer a sua atividade isoladamente, mas, quando possível, em grupos, em que a realização e a responsabilidade de um trabalho sejam atribuídas a vários indivíduos, para se habituarem a agir em cooperação, afirmando a sua personalidade, com espírito de disciplina coordenador de esforços individuais" (A reforma Fernando de Azevedo: Distrito Federal, 1927-1930. São Paulo: FEUSP, 1982, p. 114, Apud, PILETTI \& PILLETI, 2002a, p. 168). 
A par desses objetivos comuns, então, os alunos seriam conscientizados pelo professor sobre a metodologia, do "como executar" as tarefas propostas. Os alunos, com isso, deixariam o engajamento na "ética da retribuição social", passando a integrar a parte da sociedade que se tornar agente e sujeito da própria retribuição (nos termos anteriormente mencionados, de BARROS FILHO, 2015, p. 109). A seu turno, o professor ficaria com maior liberdade para respeitar nos alunos os diferentes perfis de "tempo necessário para executálas":

Como acontece com a maioria das pessoas, você provavelmente tem metas ideais para o futuro. Talvez você esteja à procura de amizades, felicidade, romance ou vida familiar satisfatória [ou sucesso no vestibular, no concurso público]. Talvez você até tenha desejos que ainda nem consegue colocar em palavras. Quando suas metas estão indefinidas, fica difícil saber por onde começar. Se você não tiver um objetivo em vista, como poderá saber se está indo pelo caminho certo e corrigir-se quando sair da trilha? (MALDONADO \& GARNER, 2000, p. 142).

É mais ou menos assim que acontece já, há décadas, com o método Problem Based Learning - PBL (cuja origem remonta o final da década de 1960, na Faculdade de Medicina, da Universidade McMaster, na cidade de Hamilton, Canadá), metodologia que instaura na sala de aula um momento para que se cumpram as fases propostas no cronograma de atividades, buscando incessantemente os resultados-alvo.

Esse procedimento, o de avaliação dos objetivos e não dos alunos, concorre para uma compreensão filosófica do processo, na abrangência das reflexões aqui apresentadas. A interação e a relativização das competências são tidas importantes para que as propostas se encaixem no modo de ver e de aproveitar o curso ou roteiro de estudos que os alunos, a instituição e/ou seus responsáveis escolheram como caminho ideal para a autorrealização do sujeito. 


\section{DISCUSSÕES SOBRE O NOVO MODELO}

O novo modelo de avaliação por metas inverteria o paradigma atual, no qual se vê que "As escolas, em geral, não estão educando para a vida. Transmitem o conhecimento de que o aluno não extrairá proveito em sua subsistência, pois divorciado [que está] das exigências concretas postas à pessoa" (NALINI, 2001, p. 227). O modelo vigente força o aluno a decidir-se diante de dois polos virtuosos: entre ser feliz ou estudar, entre ser um sujeito paciente no processo e retribuir à sociedade ou entre ser um agente proativo e compreender que a verdade do processo consiste nele mesmo e não numa recompensa a ser recebida ou numa satisfação a ser dada:

A virtude não consiste no simples conhecimento do bem, mas na sua conquista. [...] O bem fazer é o bem da ação adquirido através do hábito, e representa 0 aspecto social do ideal aristotélico. $O$ bem consiste no funcionamento, na vida social, das ideias ou princípio de conduta de validez universal. A felicidade, que é o bem supremo, consiste em realizar o que é específico do homem, isto é, a razão. A plena realização do elemento racional humano supõe a realização, nos mais diversos aspectos, tais como saúde, fortuna, situação social etc. (PILETTI \& PILETTI, 2002b, p. 66).

Assim, envolvidos dentro dos mesmos propósitos, e cada um à sua maneira de compreender o mundo, os professores, os responsáveis e os alunos se tornam componentes mais conscientes do processo, (re)valorizados e participantes simultâneos do sistema de ensino, e não vítimas alternadas desse histórico de convivência sociocultural, cuja índole repetitiva está evidentemente depauperada e superada:

A sociedade não se mostra satisfeita com sua Universidade. A própria comunidade universitária também não se aceita nos moldes como funciona. Seus alunos não se conformam com o distanciamento entre as necessidades do mundo e o acervo de conhecimentos que lhes é transmitido. Seus professores vivenciam desalento, vendo o país remunerar com generosidade os apresentadores de TV, os jogadores de futebol, as dançarinas do sensualismo e a eles reservar uma carreira medíocre, sem garantia de subsistência digna quando da aposentadoria (NALINI, 2001, p. 229). 
Nessa nova condição, de participantes aquilatados, todos os atores do processo esforçam-se para superar as próprias dificuldades e conseguir realizar para si uma parte ou a totalidade dos objetivos sociais, culturais e acadêmicos que a todos foram propostos. Como resultante, temos que o processo de aprender se torna para o aluno uma intensa, árdua, mas gratificante experiência de vida e de superação contínua. Ele não tem a obrigação de estudar para tirar nota, ele próprio tem objetivos pessoais a serem cumpridos, e seus objetivos pessoais têm ligação íntima com as metas globais do sistema socioeducativo:

A luta pelas mudanças não se limita a ser oposição ao que existe e a tentar obstruir a iniciativa e as ações das forças conservadoras. Essa é uma posição defensiva, suicida, e também conservadora. Foi assim que agiram os que se opunham à revisão constitucional, especialmente os partidos de esquerda, e só conseguiram o que a direita mais queria: conservar o grande nada de uma Constituição incompleta e mal feita. É preciso ir além dessas posições reivindicatórias e obstrucionistas. Não basta ser oposição ao sistema dominante; é preciso ser contra ele por opção a outro, claramente definido, pelo qual se possa lutar (MARTINEZ, 1997, p. 75).

Nossa proposta de avaliação por objetivos, embora preveja a possibilidade de uma não realização plena dos propósitos individuais de cada aluno, não acredita numa implicação direta disso na depreciação do resultado global de uma unidade escolar inteira. E aqui, o que era somente uma hipótese no ano de 2007, se tornou uma realidade comprovada, cujos resultados foram compilados noutro paper publicado em 2018, o que justifica plenamente a presença de uma autocitação (PESSOA, 2018).

Além disso, a oscilação da aferição e aproveitamento percentual das parcialidades - uma sala de aula ou um indivíduo - não invalida a visualização percentual relativa da consecução total das metas da escola. Assim, o resultado é só um resultado numérico, protocolar, e não um medidor de capacidade humana. Ele, o resultado, representa apenas o quanto falta para que se atinja a totalidade dos objetivos, e não o que cada partícipe do processo pensa ou deseja para si.

Durante o auge do processo, exige-se, contudo, constante percepção autoavaliativa da equipe toda, a fim de que os atrasos no cronograma de 
execução sejam minimizados: incentiva-se, desse modo, a interação entre os componentes do processo - Escola, professores, familiares responsáveis e discentes - transformando o processo de ensino-aprendizagem num momento de convívio sociocultural mais efetivo, afetivo e intenso.

A dimensão da superação e consecução dos propósitos não mais é medida pela nota, mas pelo interesse que ele, o aluno, tenha ou não em desempenhar as atividades propostas (note-se que ele mesmo as estabeleceu, diante dos conteúdos e contingências delineados pela instituição e pelos responsáveis). Logo, se ele próprio as dispôs, o interesse em executá-las é focado na força de sua própria vontade, desse modo, o aluno toma para si a responsabilidade antes prevista na "ética da retribuição social".

Documentalmente, a burocracia disso pode ser resolvida criando-se uma planilha na qual serão apostos parâmetros percentuais sobre os objetivos pessoais, e noutra, sobre os globais. O Estado, a instituição de ensino, ou quem quer que seja que exerça o papel de acompanhamento e de controle continuarão tendo como aferir a evolução, mas, agora, de uma maneira mais inclusiva da pessoa humana e de suas heterogeneidades, e cada vez mais distante de uma simples medida numérica e artificial que excluía o educando para dentro do sistema, criando um "faz de conta" institucional:

A consciência das finalidades de uma Universidade que pretenda subsistir no terceiro milênio conduzirá a uma coesão de princípios, com o trabalho em comunhão dos dirigentes, dos professores, dos alunos e do pessoal administrativo. E a Universidade imbuída de sua responsabilidade ética é solicitada a ser instrumento cada vez mais eficaz de desenvolvimento cultural para os indivíduos e para a sociedade (NALINI, 2001, p. 231).

Essa nossa proposta que transita ao redor dos domínios de uma "ética da avaliação", isto é, de uma avaliação por objetivos, contemplam-se vários outros itens que interferem na dinâmica do contexto interno e externo às salas de aula, tais como as variantes socioculturais e econômicas componentes das heterogeneidades acadêmicas.

Uma nova sociedade, tal qual a que se desenha durante a Pandemia de COVID-19 no mundo, pede uma reflexão que conduza para uma nova escola, a uma nova relação de ensino-aprendizagem que produza também uma nova 
dinâmica de interação sociocultural, bem aos moldes aos quais os escolanovistas já preconizavam:

Em contraposição, a escola nova assim se representa: baseia-se na iniciativa do aluno; preocupa-se como que a criança pode realmente aprender; valoriza as tendências espontâneas da criança; os professores sugerem, orientam e coordenam; os métodos, programas e horários são maleáveis; visa às noções utilizáveis; é essencialmente educativa, está mais próxima do meio natural de vida; busca o aperfeiçoamento; eleva a natureza moral do aluno; procura individualizar o ensino, produzindo satisfação; atende mais ao presente; trata a criança com criança; propõe uma atividade produtiva; obtém a disciplina voluntária ( $A$ reforma Fernando de Azevedo: Distrito Federal, 1927-1930. São Paulo: FEUSP, 1982, p. 114, Apud, PILETTI \& PILLETI, 2002a, p. 169).

Enfim, a ética da avaliação quanto à aquisição do conhecimento deve ser capaz de prever novas ferramentas que nos permitam conviver melhor numa nova sociedade chamada de pós-moderna:

A revolução da informação, o fim da guerra fria - com a decorrente hegemonia de uma superpotência única - e a internacionalização da economia impuseram um novo equilíbrio de forças nas relações humanas e sociais que parece jogar por terra as antigas aspirações de solidariedade e justiça distributiva entre os homens, tão presentes nos sonhos, utopias e projetos políticos nos últimos dois séculos (ROITMAN, 2003, p. 10).

Vale lembrar que avaliando as metas, são levados em consideração fatores normalmente ignorados, mas extremamente relevantes nessa interação executiva do aluno com o conteúdo ministrado, tais como classe social, situação econômico-financeira, as diferenças psíquicas e orgânicas, os desnivelamentos culturais e curriculares oriundos das séries de base, e, também, a estabilidade ou a instabilidade emocional do aluno no momento da realização da avaliação tradicional, tudo isso contribuindo isoladamente ou em conjunto para a construção de um perfil de aluno, o qual denominamos de heterogêneo e que são colocados de lado no fragor das práticas avaliativas rotineiras:

Em outras palavras: exige-se que a pessoa em questão não esteja submetida a uma coação externa. Quando o agente moral está sob 
pressão de uma coação externa [exercida nesse caso pela escola], perde [o aluno] o controle dos seus atos, sendo-lhe fechado o caminho da eleição e da decisão pessoais, razão pela qual realiza um ato nem escolhido nem decidido pessoalmente. Na medida em que a causa do ato está fora do agente, escapando ao seu poder e controle, e em que se lhe barra a possibilidade de decidir e agir de outra maneira, não se pode responsabilizá-lo pelo modo como agiu (VÁZQUEZ, 2006, p. 113).

Nesses termos, percebemos que o ser humano pode ser reintegrado, por meio de nossa proposta de avaliação por objetivos, como sujeito ativo ao ambiente sociocultural do ensino-aprendizagem.

Quanto a nossa pergunta ${ }^{5}$, portanto, a resposta, para os efeitos pretendidos a partir desse nosso texto, isto é, reintegrar o sujeito humano ao sistema educacional sob a égide de um novo status quo - o de partícipe, e não o de vítima manipulada do processo -, é que não. Pois, aplicando-se o procedimento por nós proposto, o de se avaliar os objetivos e não os alunos, o que se obtém como resultado não é um contingente de alunos bons e outros ruins, mas um indicador aproximado do quanto avançamos na consecução de uma meta. Enquanto isso, professores e demais responsáveis (diretores da instituição, familiares, colegas de sala), se debruçam em compreender em que fase do cronograma certos itens não foram cumpridos, interrompidos ou realizados com maior vagar.

A maneira pela qual deveríamos entender o hábito de ensinar e de aprender - ou seja, o "processo ético de avaliação" - (e não o "momento, performático ou burocrático" ou o "lapso" de tempo destinado às provas de hoje em dia), portanto, não se reduz às notas iguais que aparentemente homogeneízam os alunos, ou às notas diferentes que os estigmatizam e os excluem.

O melhor olhar sobre o sistema deveria abranger todo o mecanismo que hoje é burocraticamente padronizado, aparato este que trata da avaliação à qual se submeteria atualmente esse alunado. Essa padronização do aparato de avaliação se materializaria ao congregarem-se elementos que vão desde a elaboração de questões iguais para todos os alunos, a uma data pré-

\footnotetext{
${ }^{5}$ Quando conferimos a um grupo de alunos (heterogêneos pela natureza das diferenças expostas acima), de uma mesma sala de aula, uma mesma nota, estaríamos homogeneizando por meio das notas alunos que são originariamente heterogêneos?
} 
determinada para a realização das provas - momento tipicamente de coação, como salientou VÁZQUEZ (2006).

Por meio desses dois aspectos (padronização e datas fixas, por exemplo) que são essencialmente de cunho administrativos e que atual coercitivamente sobre o psicológico discente, pretende-se que todos os alunos estejam, ao mesmo tempo, em pé de igualdade de conhecimento ou em plenas condições de dar as respostas certas (corretas segundo o modelo do sistema).

Ao mesmo tempo, portanto, a gerência educacional espera que os alunos, que são naturalmente diferentes em compreensão e desejos, e, portanto, vivendo em estágios socioculturais distintos dentro do processo de aprendizagem, demonstrem artificialmente uma proficiência mínima de conhecimentos - têm que tirar "média" -, a fim de não comprometerem o bimestre seguinte ou que se verifique simplesmente, por meio das notas, os que conseguiram ou os que não conseguiram "passar de ano":

Esta avaliação discernente mostra como a campanha mensal para atingir alvos pode solapar o clima de confiança, tão importante para a conduta ética. $O$ fato de padrões de qualidade serem mantidos redunda em crédito para gerentes e chefes de seção nesse departamento [no nosso caso, direção e burocracia do sistema educacional], embora a repetida necessidade de evitar fracassos quase imponha uma forte tensão a essas pessoas - tensão que foi considerada uma questão ética por pelo menos um dos interessados: "Fico preocupado em pôr o pessoal dentro de uma panela de pressão ao fim de todos os meses. De que maneira isso os afeta? (AGUILAR, 1996, p. 104).

Desse engodo no gerenciamento acadêmico, resultam pelo menos duas coisas: se há algo que homogeneíza o aluno é o sistema padronizado de avaliação ao qual se submetem hoje os discentes, sistema que atende mais ao preenchimento de quesitos burocráticos criados pelos gestores do aparato educacional do que à visualização do aprendizado efetivo e consistente dos conteúdos ministrados.

Outro fator que deriva dessa gestão acadêmica equivocada é o fato de que o ente humano, naturalmente heterogêneo, tendo de demonstrar uma proficiência intelectual homogeneizada pela necessidade burocrática de enquadramento ao critério de uma "nota média", sente-se oprimido ou desmotivado e acaba construindo em torno de si expedientes auxiliares para 
compensar as deficiências individuais oriundas, muitas vezes, mais do descompasso entre o tempo em que se ensina e o tempo em que realmente se aprende, do que em função de uma provável incompetência intelectual sua naquele momento.

A experiência docente assevera que consistem os tais "aparatos auxiliares", de métodos condenáveis quase como se fossem pecados capitais: o "decoreba", a "cola", a "troca de provas", as "escutas eletrônicas" etc. Esses dilemas devem ser discutidos sob a redoma da ciência ética. Um sistema de avaliação que não seja ético, sob o ponto de vista metodológico, não pode esperar que aqueles que a ele se submetem devam ser éticos.

É claro que coextensivamente, por exemplo, sabendo-se que a regra do jogo capitalista é a privação de itens necessários a muitos em favor do supérfluo de poucos, que, desse modo, justificar-se-iam a violência e os crimes de subtração do patrimônio alheio. O que queremos dizer, é que, do mesmo modo, esses dilemas envolvem questões éticas sobre a avaliação, devem sugerir uma reflexão, e que as soluções sejam pensadas, organizadas e implementadas sob a batuta de uma necessária revisão ética nas instituições:

Quanto menos culta uma classe, mais vulnerável se torna a sociedade; quanto menos culta uma nação, mais susceptível se torna de ser dominada. A ignorância facilita o enfraquecimento da virtude e o erro pode consagrar-se com conduta aceitável perante o social, o que se tornar ético na prática, todavia, jamais se poderá aceitar como verdade da doutrina da Ética e aí se diferenciam as qualidades das consciências (SÁ, 2007, p. 82).

Embora enxerguemos nos expedientes mencionados uma "ética da cavilação", sabemos que estes são tão condenáveis quanto difundidos. É deles que se utilizam as instituições para promover ou reter os avaliandos,

Isso acontece justamente num momento em, para muitos deles, o conhecimento ainda está em processo de maturação em suas mentes. É mais ou menos o que ocorre quando se exige de uma criança, que ainda não tem toda a sua bainha de mielina constituída, um raciocínio muito avançado para a sua faixa etária: ou ela não consegue, ou "chuta" uma alternativa, ou inventa uma resposta legal, ou simplesmente chora. 
Ou seja, beira ao absurdo crer-se que tal procedimento absolutizante e homogêneo de avaliação vigente seja eficiente e verdadeiro quanto aos resultados que demonstra. $\mathrm{O}$ que se verifica com frequência é que o aluno que normalmente "tira dez" nas provas periódicas do sistema, dias depois não tem a mínima noção do conteúdo que, aparentemente, dominava plenamente dias antes - esse é mais um viés do "faz de conta" patrocinado pelo sistema.

$E$, se isso é assim, todos - alunos, professores e instituições -, parecem estar perdendo muito tempo preenchendo gráficos, planilhas e provas nos "ENEMs" oficiais que ratificam oficialmente para o Ministério da Cultura e para as Delegacias Municipais e Estaduais de Ensino, a "magia" mentirosa deste "faz de conta" educacional coletivo:

Os especialistas dos programas e da avaliação padronizada podem apresentar essas capacidades gerais como competências, jogando com as ambiguidades do conceito ou, em uma posição defensiva, considerálas como elementos ou ingredientes gerais de múltiplas competências. $\mathrm{Na}$ falta de formar somente competências, a escola poderia, ao menos, além de fornecer conhecimentos, trabalhar capacidades descontextualizadas - sem referência a situações específicas - porém "contextualizáveis", tais como saber explicar, saber interrogar-se ou saber raciocinar (PERRENOUD, 1999, p. 45).

Nesse contexto, a realidade objetiva apresenta um efeito em cadeia de incompetências: é comum encontrarem-se advogados que não conhecem os códigos legais básicos, juízes que não sabem interpretar corretamente as Leis, professores de português que não sabem a gramática da língua, médicos que não fazem diagnósticos corretos, engenheiros que constroem construções frágeis etc.

Outra consequência danosa disso fica por conta de que, assim se mantendo, a parcela do sistema educacional que procede desse modo está fadada a uma falência por inanição. Noutros termos, isto quer dizer que, enquanto os alunos ostentam no boletim acadêmico notas altas, maior é, paradoxalmente, o grau de ineficiência do instrumento absolutizante conhecido como avaliação, e mais baixa tende a ser a qualidade do profissional que por meio dela as instituições de ensino entregam ao mercado de trabalho e à sociedade. 


\section{CONCLUSÃO}

A opacidade da rede costuma dar abrigo a quem não pode assumir o que faz (BARROS FILHO, 2015, p. 04).

Se o pensamento de que o paradigma educacional sobre a avaliação precisa ser revisto não é totalmente verdadeiro, também não se pode dizer que ele nos induz a conclusões totalmente falsas, uma vez que, uma das principais funções da avaliação absoluta nos moldes atuais, é visar atender mais a critérios burocráticos e normativos das secretarias escolares do que, precipuamente, organizar estratégias alternativas para minimizar as deficiências qualitativas dos alunos durante o processo socioeducativo.

Ao dizer-se nos projetos pedagógicos que os alunos são de perfil sociocultural heterogêneo, e consequentemente dotados de diversas particularidades que os distinguem entre si, e que, mesmo assim, têm que fazer uma prova homogênea, no mesmo dia, no mesmo horário, sobre um mesmo conteúdo, e que eles terão que apresentar no mínimo uma nota média, 07 (sete), por exemplo, pratica-se um absurdo acadêmico e abre-se uma fenda ética no sistema.

Nesses projetos, e em quase todos, sem exceção, estão elencados os perfis do aluno ingressante e do egresso, em que são destacados, via de regra, o caráter heterogêneo dos partícipes do processo de ensino-aprendizagem. Existe uma heterogeneidade teórica que, na prática, é ignorada. Ao nos sujeitarmos a tal inconsistência em nome de uma suposta "lei geral da Educação", estaríamos sendo submissos ou atuando como sujeitos adaptados:

A obediência à lei, fruto de razão somada à piedade, não seria um ato de submissão, mas de liberdade. Quanto mais a sociedade possuísse leis, jurídicas ou morais, oriundas dessa vontade geral, mais livres seríamos, mesmo quando nos opuséssemos a essas normas, mesmo que fôssemos obrigados a segui-las. Se não as obedecemos por vontade própria, a ponto de ser necessária a força para nos constranger, é porque somos capazes de agir contra a nossa piedade. $E$, portanto, impor a lei fruto da vontade geral seria impor sobre nós a nossa própria natureza (BARROS FILHO, 2015, p. 81). 
O que é óbvio, e o que também olvidamos nesse cenário, é que a "ética da aprendizagem" do ser humano mostra que ele aprende relativizando experiências, pautando-se uns em relação aos outros, de "maneiras distintas" e em "velocidades distintas" de assimilação.

Quanto à maneira distinta de aprender, o professor até poderia criar uma prova individual, contemplando o perfil de cada aluno, e estabelecer um critério que os avaliasse considerando as individualidades, a partir, então, de algumas de suas faculdades perceptivas: há alunos que aprendem muito mais visualizando os conteúdos - os chamados "visuais" -, outros, ouvindo conhecidos como "auditivos" -, outra fração de alunos, escrevendo, ou transcrevendo conteúdos - os "sinestésicos", como se alude nos pressupostos da Escola Nova. Haveria, ainda, outro grupo que contemplaria, em graus mais ou menos proporcionais, um pouco das três habilidades cognitivas mencionadas. Haveria também os que, dialogando, conseguiriam melhor desempenho, pois têm a inteligência emocional mais à flor da pele.

A expectativa, portanto, seria a de que, por meio de provas individualizadas, se chegasse a um resultado mais próximo da "verdade" do conhecimento apreendido pelo educando. No entanto, reconhecemos que essa individualização da prova teria resolvido, apenas e parcialmente, a questão pertinente à "maneira", ou do "jeito" específico e individualizado, por meio do qual cada aluno efetivamente aprende.

Restaria, ainda, a importante questão de se tentar identificar o "porquê" cada aluno aprende ou prefere aprender. Levando-se em consideração que cada ser humano é dotado de uma visão particularizada dentro do sistema sociocultural ao qual se insere, entenderíamos também que ele é possuidor de uma singularidade orgânica e psíquica, e que a utiliza de uma forma imprecisa e distinta dos demais membros do seu grupo social.

Conclui-se, enfim, que esse ser, investido do papel sociocultural e temporário de "aluno", tem, também, uma diferenciação na dinâmica (velocidade ou tempo) também imprecisa de apreensão dos conteúdos, imprecisão esta que é proporcional à medida abstrata de suas diferenças pessoais intrínsecas e de sua vontade em captar ou não aquilo que the é 
oferecido sob o rótulo de "conhecimento necessário" para o bom convívio nos moldes contemporâneos de civilização.

Em outras palavras, estamos dizendo que cada aluno tem um tempo e desejo diferenciado, relativo, específico e indeterminado para que compreenda e aceite efetivamente tudo o que lhe foi ensinado, e que o instrumento avaliação, burocraticamente padronizado e direcionado periodicamente sobre o aluno, considerado como instrumento de verificação dessa assimilação, nem sempre coincide com o melhor momento de cada um dentro do processo global de ensino. Quando isso ocorre, por ocasião das avaliações tradicionais, o que se observa é que as "notas" diferentes (04, para uns, 05, para outros, outros tantos com 09, e um ou dois com 10) refletem mais o descompasso inequívoco do processo de aprendizagem de cada um (vale ressaltar que, para essa constatação, nem seria preciso a aplicação de uma avaliação, já que, ao olharmos à nossa volta, enxergamos as óbvias diferenças entre os humanos) do que necessariamente a realidade das discrepâncias intelectuais, ou do efetivo aproveitamento de cada aluno em relação aos conteúdos ministrados.

Temos, finalmente, o grande nó do problema. De um lado, na condição ambígua de professor e de avaliador e, portanto, um personagem protagonista do sistema educacional que tenta entender concretamente o "como" o "quando" e o "porquê" esse aluno aprende abstratamente. E, de outro lado, outra face do mesmo ator que, apesar de conhecer as particularidades as quais cada aluno traz consigo, impõe-lhes um mecanismo de avaliação recrudescente que ignora suas diferenças, exigindo deles um compromisso, não com o efetivo aprendizado e com o conhecimento, mas com a burocracia do aparato regulador e disciplinador do Estado e das Instituições de Ensino, legitimado pelo silêncio da sociedade e da família como um todo, mas praticamente incompatível com os novos fundamentos transformadores da sociedade pósmoderna.

Nesse contexto colidem, portanto, os universos da "ética da responsabilidade" e a "ética do compromisso", protagonizadas respectivamente por professores, de um lado, e por alunos, de outro. Entre uns e outros, as instituições Escola e Sociedade, jazendo indecisas entre a praxis do que são e o projeto do que poderiam ser. 


\section{REFERÊNCIAS}

AGUILAR, Francis J. A Ética nas Empresas. Rio de Janeiro: Zahar, 1996.

BAUMAN, Zygmunt. Ética Pós-moderna. São Paulo: Paulus, 1997.

BARROS FILHO, Clóvis de. Somos Todos Canalhas. Rio de Janeiro: Casa da Palavra, 2015.

FREITAG, Bárbara. Escola, Estado \& Sociedade. São Paulo: Moraes, 1980.

HABERMAS, Jürgen. O Discurso Filosófico da Modernidade. São Paulo: Martins Fontes, 2002.

HALL, Stuart. A Identidade Cultural na Pós-modernidade. Rio de Janeiro: DP\& A, 2006.

KELLER, Helen. Lutando Contra as Trevas. Rio de Janeiro: Editora Fundo de Cultura, 1957.

LDB. Diretrizes e Bases da Educação Nacional. Brasília: Câmara dos Deputados, Coordenação de Publicações, 2001.

MALDONADO, Maria Tereza \& GARNER, Alan. A Arte da Conversa e do Convívio. São Paulo: Saraiva, 2000.

MARTINEZ, Paulo. Poder e Cidadania. Campinas: Papirus, 1997.

MIZUKAMI, Maria da Graça Nicoletti. Ensino: as abordagens do processo. São Paulo: EPU, 1986.

NALINI, José Renato. Ética Geral e Profissional. São Paulo: Editora Revista dos Tribunais, 2001.

PERRENOUD, Philippe. Construir as Competências desde a Escola. Porto Alegre: Artmed, 1999.

PESSOA, Marcelo. GRUPO DE PESQUISA SIC - Sociedade, Imagens e Cultura: dados de pesquisa básica, intermediária e avançada - 2011 a 2017. São Carlos: CIET: ENPED, 2018. ANAIS DO CIET: ENPED. São Carlos - SP: EdUFSCAR, 2018. v. 3. p. 1-11.

PILETTI, Nelson \& PILETTI, Claudino. História da Educação. São Paulo: Ática, $2002 a$.

PILETTI, Claudino \& PILETTI, Nelson. Filosofia e História da Educação. São Paulo: Ática, 2002b.

ROITMAN, Ari (org.). O Desafio Ético. Rio de Janeiro: Garamond, 2003.

PNC +, Ensino Médio. Linguagens, Códigos e Suas Tecnologias. Disponível em http://portal.mec.gov.br/seb/arquivos/pdf/linguagens02.pdf, acesso em $20 / 05 / 08$, às 17:40h.

SÁ, Antonio Lopes de. Ética Profissional. São Paulo: Atlas, 2007.

VÁZQUEZ, Adolfo Sánchez. Ética. Rio de Janeiro: Civilização Brasileira, 2006. 